\title{
A school-based resilience intervention to decrease tobacco, alcohol and marijuana use in high school students
}

\author{
Rebecca K Hodder ${ }^{1,2,3^{*}+}$, Justine Daly ${ }^{1,2,3,5 \dagger}$, Megan Freund ${ }^{1,2,3,4 \dagger}$, Jenny Bowman ${ }^{2,3 \dagger}$, Trevor Hazell ${ }^{2,3,5 \dagger}$ and \\ John Wiggers $1,2,3,4+$
}

\begin{abstract}
Background: Despite schools theoretically being an ideal setting for accessing adolescents and preventing initiation of substance use, there is limited evidence of effective interventions in this setting. Resilience theory provides one approach to achieving such an outcome through improving adolescent mental well-being and resilience. A study was undertaken to examine the potential effectiveness of such an intervention approach in improving adolescent resilience and protective factor scores; and reducing the prevalence of adolescent tobacco, alcohol and marijuana use in three high schools.

Methods: A non-controlled before and after study was undertaken. Data regarding student resilience and protective factors, and measures of tobacco, alcohol and marijuana use were collected from grade 7 to 10 students at baseline $(n=1449)$ and one year following a three year intervention $(n=1205)$.

Results: Significantly higher resilience and protective factors scores, and significantly lower prevalence of substance use were evident at follow up.

Conclusions: The results suggest that the intervention has the potential to increase resilience and protective factors, and to decrease the use of tobacco, alcohol and marijuana by adolescents. Further more rigorous research is required to confirm this potential.
\end{abstract}

\section{Background}

Tobacco, alcohol and other drug use contribute significantly to mortality and morbidity in many countries $[1,2]$. Tobacco use generally commences in early adolescence [3], with earlier uptake associated with heavier smoking [4], rapid establishment of nicotine dependence even after brief intermittent use [5] and greater difficulty in quitting in adulthood [4]. Similar to tobacco, initiation of alcohol use generally occurs in adolescence [6], and earlier drinking experiences have been linked to alcohol dependence in adulthood [7]. The patterns of illicit substance misuse developed in youth are similarly associated with continued use into adult life [8]. World wide, a significant proportion of adolescents use

\footnotetext{
* Correspondence: rebecca.hodder@hnehealth.nsw.gov.au

† Contributed equally

${ }^{1}$ Hunter New England Population Health, Hunter New England Area Health Service, New South Wales, Australia Full list of author information is available at the end of the article
}

tobacco, alcohol and marijuana, with such use being greater in older adolescent age groups [9-13].

Schools are considered an ideal setting for programs aimed at decreasing the prevalence of health risk behaviours as: they provide access to young people at a time when they are vulnerable to emotional problems and risk taking behaviour [14]; young people spend half their waking hours at school; and the quality of experiences with teachers and peers can have a positive impact on young people's health and emotional well-being [15]. Despite such potential, reviews of school-based programs designed to reduce the prevalence of tobacco and alcohol use have found conflicting or little evidence of effect [16-19]. In particular, interventions focused on the provision of information (for example, interventions that only include information-giving curricula [20]) have been suggested to be ineffective [19]. A World Health Organisation review of school health promotion
C Biomed Central 
interventions further concluded that programs promoting young people's mental well-being were the most likely to be effective, recommending such an approach be the focus of future studies targeting adolescent substance use [18]. The review also suggested that interventions that incorporate changes in the school curriculum, the school environment and that foster relationships between schools and their communities were the most likely to achieve a beneficial outcome, an approach known as the 'health promoting schools' framework [18]. Such a view is supported by research that identifies school culture to be a determinant of substance use [21,22].

Resilience theory, which has arisen from the study of risk factors and their impact on positive youth development, represents one approach to improving adolescent mental well-being [23-29]. Whilst there is much variation in the definition of resilience, it is generally agreed that both individual as well as environmental characteristics contribute to individual resilience and are critical for positive youth development and the avoidance of risk behaviours [30-33]. Individual characteristics, termed resilience factors, refer to the personal skills and traits of young people, and include self-esteem, empathy, help-seeking and self-awareness [34]. Where as protective factors refer to positive influences within a young person's environment such as family, school, and community connection [34]. As associations between such characteristics and substance use have been reported [35-37], interventions designed to increase such factors may represent a means of reducing the extent of adolescent substance use uptake.

Although a number of school-based trials have targeted resilience or protective factors to reduce substance use [34,38-42], no controlled studies could be identified that described the effectiveness of an intervention that targeted both types of factors using the health promoting schools framework. Of the controlled trials that have incorporated a focus on either resilience or protective factors, inconsistent effects on tobacco, alcohol and marijuana use have been reported [34,38-42]. For example, in Australia, a three year cluster randomized controlled trial involving 26 secondary schools assessed the effect of a social and school connectedness intervention on student tobacco, alcohol and marijuana use $[40,40]$. One and two year follow up data were collected for a cohort of students recruited in Grade 8. At one year follow up (students in Grade 9), a significantly greater reduction in substance use was only found for smoking [40], whilst at two year follow up (students in Grade 10) no significant effect was found for smoking or alcohol, but a significant reduction in marijuana use was found [39]. On further subgroup examination the authors found a greater intervention effect for marijuana use in Grade 10 if students were nonsmokers in Grade 7 and for those who reported the lowest level of school engagement in Grade 8 and 9 [39]. The authors concluding this type of intervention may only be effective if implemented prior to initiation to tobacco smoking and for those students considering experimentation with marijuana use who are least engaged in school [39]. This conclusion is supported by studies that have demonstrated exposure to intervention prior to target problem uptake is predictive of greater effectiveness [43].

One non-controlled evaluation of an intervention addressing both resilience and protective factors using a health promoting schools approach has been reported $[34,41]$. The intervention aimed to reduce risk behaviours, including tobacco, alcohol and marijuana use, among students in fifteen non-randomly selected Australian secondary schools. Using a cross sectional design, three year follow up data were obtained from students in Grades 7 to $11[34,41]$. No significant effect on substance use was found. In addition, of 30 post hoc analyses by student grade and gender, significant reductions were found in only six cases: smoking by Grade 7 males and by Grade 8 males and females; alcohol use by Grade 7 males and Grade 8 females; and marijuana use by Grade 9 males.

A separate process evaluation was conducted after the initial non-controlled evaluation to identify factors that may have contributed to these inconsistent results. The authors identified limited uptake of the intervention by schools, in particular, a whole of school approach to intervention adoption was implemented by less than half of schools, only one-third had implemented recommended intervention planning and monitoring mechanisms, and only $20 \%$ had developed recommended relationships with external agencies [41]. Interviews with school staff identified a number of barriers to intervention implementation including: inadequate resources; inadequate levels of school staff professional development; inadequate school executive support; and the importance of funding to ensure sustainability [41]. Such barriers are consistent with those suggested by other studies to limit intervention uptake and fidelity, and hence intervention effect [44-46]. These findings, combined with those from other school-based studies which recommend comprehensive and systematic approaches to intervention implementation [29], suggest that future interventions of this type include explicit strategies to address such barriers and foster intervention uptake and fidelity. Despite this, whilst studies addressing student resilience have since reported some adoption strategies [40], at the time of development no studies could be located that reported explicit and comprehensive program adoption strategies. 
Given the limited number of studies examining the effect of comprehensive interventions that address both resilience and protective factors on adolescent substance use, and the lack of reported studies that report the use of strategies to support the adoption of such an intervention, the aim of this pilot study was to examine the potential efficacy of a resilience-based intervention supported by adoption strategies on modifying adolescent resilience and the extent of adolescent substance use uptake.

\section{Methods}

\section{Design}

A non-controlled repeat cross sectional study was undertaken. The intervention was implemented over 3 years in each school across Grades 7 to 10 . Cross sectional data were collected prior to intervention implementation and again 12 months following completion. The outcome measures of interest were student reported resilience and protective factor scores, and tobacco, alcohol and marijuana use.

\section{Setting and sample Schools}

Three public high schools were selected on a convenience basis. The schools were located within a 15 kilometre radius of each other in one regional area [47] of New South Wales, Australia. The region has a population of approximately 50,000 people, with an estimated 3,600 people aged 12 to 16 [48], and is ranked in the lowest quintile of socio-economic disadvantage using 2006 Australian Bureau of Statistics SEIFA Index of Relative Socio-Economic Disadvantage [49]. Ethics approval was obtained from the New South Wales Department of Health.

\section{Students}

The data were collected in August 2002 (baseline) and June 2006 (follow-up). At baseline, the schools ranged in size from 593 to 1011 students. All Grade 7-10 students (aged 12-16 years) attending the three high schools were eligible to participate (2002: $\mathrm{n}=1899$; 2006: $n=1965)$. Students were blinded to the study aim of decreasing health risk behaviours.

\section{Procedures \\ Recruitment and consent}

An information letter and consent form were provided to each student by the school to obtain parental consent. Non-responding parents were followed up by phone to prompt return of the consent form.

\section{Resilience and protective factor intervention}

A multi-strategic intervention based upon an existing student resilience and protective factor program was implemented [50]. Data obtained from a baseline survey were used to inform the selection of resilience and protective factor intervention strategies in each of the three health promoting schools domains: curriculum, teaching and learning; ethos and environment; and partnerships and services [18].

Curriculum, teaching and learning Strategies involved the implementation of various curriculum materials and programs designed to enhance student resilience and protective characteristics including curriculum materials designed to enhance student communication, connectedness, empathy and self-awareness across all grade [50]; and implementation of programs targeting particular resilience and protective factors, such as the Rock and Water Program [51] or the Resourceful Adolescent Program [52].

Ethos and environment Strategies involved the development and modification of school policies and programs relating to bullying to increase school connectedness, enhancement of peer support program to increase school connection and self esteem, and student recognition programs to enhance student autonomy, goals and aspirations via acknowledgement of student achievements.

Partnerships and services Strategies involved schools forming formal partnerships with local services to provide youth services access within school hours to enhance help seeking, initiatives to promote greater parent involvement via active engagement in schoolinitiated activities and promotion of links with community organisations with the school.

\section{Strategies to enhance school intervention adoption}

To maximise intervention adoption by schools the following strategies were implemented based on evidence of their effectiveness in supporting practice change in human service organisations [53] and findings from other school-based studies [29,41,45,46,54,55]:

Local consensus and adaptation A number of strategies were implemented to ensure appropriate leadership support was available during intervention implementation, and the strategies implemented were feasible and able to be integrated within existing school systems [45]. Strategies implemented at each school included: the development of a memorandum of understanding to outlining the partnership between, and the roles of, schools and researchers [56]; formation of an advisory group to guide the intervention; establishment of core teams to implement the intervention [55]; and intervention planning workshops for school staff, parents and community members [45].

School action plan and performance monitoring A school action plan [54] was developed by each school based on the results of biennial student resilience and protective factors surveys. The surveys further provided a means of monitoring and reviewing the action plan implementation and effectiveness, with schools being provided reports of their student results. 
Staff training Core staff from each school participated in annual training programs to increase their capacity to address student resilience, communication, connectedness, empathy and self-awareness [34].

Provision of intervention implementation resources One full time research assistant was employed for three years to support the three schools to implement the intervention. In addition, for the two initial intervention years, funding was provided to each school to facilitate teacher participation in training, planning and implementation of the intervention (AUS $\$ 4,000$ and AUS $\$ 5,000$ respectively per school).

\section{Data collection}

Students at each school completed a pen and paper survey conducted within class time at both baseline and follow up data collection. The survey included items addressing student resilience and protective factor characteristics, and their substance use behaviours.

\section{Measures}

Resilience and protective factor scores The survey, based on the resilience module from the California Healthy Kids Survey [30,34,57], included items relating to six resilience and six protective factor subscales. The six resilience factor subscales included items addressing the following: empathy (2 questions), effective help seeking (3 questions), self esteem (3 questions), communication and cooperation (2 questions), self awareness (2 questions), and goals and aspirations (2 questions). The six protective factor subscales included items regarding: family connection (4 questions), pro-social peers (3 questions), autonomy experience (4 questions), community connection (4 questions), school connection (4 questions), and pro-social group (3 questions). Students responded to each question using a four-point Likert scale ranging from ' 1 - never true', to ' 4 - true all of the time'. The subscales have been shown to have excellent to adequate internal reliability (resilience factors $\mathrm{a}=0.53-0.78$; protective factors $\mathrm{a}=$ 0.69-0.89) [34] and to be reliable and valid in an Australian school population [58].

Tobacco, alcohol and marijuana use prevalence Questions regarding student use of tobacco (3 questions), alcohol (2 questions) and marijuana (1 question) were based on items from previous surveys conducted within New South Wales secondary schools (Table 1) [11,34].

Student characteristics Students were asked to specify their grade and gender.

\section{Analysis}

\section{Sample characteristics}

Student descriptive characteristics (gender and grade) at baseline and follow up were compared using Chi square analysis.

\section{Resilience and protective factor scores}

At baseline and follow up, individual student scores for each of the six resilience and six protective factor subscales were calculated by averaging responses to questions in each subscale. An overall resilience and protective factor score for each student was calculated by summing these subscale scores.

Resilience factor and protective factor scores for each school, and for all three schools combined, were calculated by averaging all individual student scores. As such scores were not normally distributed, median scores are reported, and differences between scores at baseline and follow up were examined using the Fisher Exact Test (non-parametric ANOVA).

\section{Prevalence of tobacco, alcohol and marijuana use}

Responses to the tobacco, alcohol and marijuana use items were categorised to form six outcome measures: use of tobacco, alcohol, and marijuana in the last three months (any, none); ever smoked a cigarette (yes, no);

Table 1 Student health risk behaviour items

\begin{tabular}{|c|c|}
\hline Health risk behaviours questions & Responses \\
\hline \multicolumn{2}{|l|}{ Tobacco } \\
\hline Have you ever smoked even part of a cigarette? & $\begin{array}{l}\text { No; Yes, just a few puffs; Yes, less than } 10 \text { cigarettes in the last } 3 \text { months; Yes, } \\
\text { between } 10 \text { and } 100 \text { cigarettes in the last } 3 \text { months; Yes, more than } 100 \text { cigarettes } \\
\text { in the last } 3 \text { months. }{ }^{\text {a }}\end{array}$ \\
\hline $\begin{array}{l}\text { In the last } 3 \text { months I have smoked one or more cigarettes } \\
\text { on: }\end{array}$ & No days; 1 day; 2 days; 3 days; 4-5 days; 6-10 days; More than 10 days. ${ }^{b}$ \\
\hline At the present time, do you smoke cigarettes: & Daily; At least once a week; Less than once a week; Not at all. \\
\hline \multicolumn{2}{|l|}{ Alcohol } \\
\hline $\begin{array}{l}\text { In the last } 3 \text { months I have had one or more drinks of beer, } \\
\text { wine or spirits (do not count sips or tastes) on: }\end{array}$ & No days; 1 day; 2 days; 3 days; 4-5 days; 6-10 days; More than 10 days. ${ }^{\text {b }}$ \\
\hline $\begin{array}{l}\text { In the last four weeks, how many times have you had } 5 \text { or } \\
\text { more alcoholic drinks in a row? }\end{array}$ & None; Once; Twice; 3-6 times; 7 or more times. \\
\hline \multicolumn{2}{|l|}{ Marijuana } \\
\hline In the last 3 months I have used marijuana on: & No days; 1 day; 2 days; 3 days; 4-5 days; 6-10 days; More than 10 days. ${ }^{\text {b }}$ \\
\hline
\end{tabular}

${ }^{a}$ New South Wales School Students Health Behaviour Survey [11]

${ }^{\mathrm{b}}$ MindMatters Evaluation Project [34] 
current smoking (yes, no); and consumption of five or more alcohol drinks in a row in the last four weeks (any, none). Differences between baseline and follow up in the proportion of students reporting each of the six outcomes were examined by Chi square analysis for all three schools combined, for each school separately, and by grade and gender. A significance level of $p \leq 0.01$ was used to adjust for multiple testing for substance use outcomes [59].

All analyses were undertaken using SAS Software Version 8.2 [60].

\section{Sample size}

Allowing for a potential intra school correlation of 0.01 [61], and a response rate of $50 \%$, a difference in resilience and protective factor scores for the three schools combined of 0.8 was estimated to be detectable based on a sample size of 900 students at the three schools at baseline and follow up ( $80 \%$ power, $p=0.05$ ). Using these same parameters [62] and a baseline prevalence of $50 \%$, a $10 \%$ difference in student reported tobacco, alcohol and marijuana use was estimated to be detectable.

\section{Results}

\section{Student sample}

At baseline and follow up, 1449 (76.3\%) and 1205 (61.3\%) students respectively with parental consent participated in the study (Table 2 ). The proportion of females $(p=0.14)$, and the proportion of students by grade $(p=0.32)$ who participated in follow up data collection were not significantly different to those participating at baseline. The gender and grade characteristics of participating students at both data collection points

Table 2 Participant descriptors

\begin{tabular}{cccc}
\hline Participant Descriptors & $\begin{array}{c}\mathbf{2 0 0 2} \\
\mathbf{n}(\%)\end{array}$ & $\begin{array}{c}\mathbf{2 0 0 6} \\
\mathbf{n}(\%)\end{array}$ & $\boldsymbol{p}$ value \\
\hline $\begin{array}{c}\text { TOTAL } \\
\text { School }\end{array}$ & $1449(76.3)$ & $1205(61.3)$ & \\
A & $425(78.0)$ & $331(69.0)$ & $p=0.34$ \\
B & $577(79.8)$ & $514(62.8)$ & \\
C & $447(70.7)$ & $360(54.0)$ & \\
Gender & & & \\
Female & $709^{c}$ & $626^{\mathrm{d}}$ & $p=0.13$ \\
Male & 734 & 577 & \\
Grade & & & \\
7 & $383^{\mathrm{a}}$ & $318^{\mathrm{b}}$ & $p=0.32$ \\
8 & 358 & 317 & \\
9 & 335 & 298 & \\
10 & 367 & 271 & \\
\hline
\end{tabular}

${ }^{\mathrm{a}} 6$ students did not provide gender

${ }^{b} 2$ students did not provide gender

'6 students did not provide grade

${ }^{d} 1$ student did not provide grade were similar to students in New South Wales public secondary schools [63].

\section{Intervention delivery}

The intervention strategies implemented by schools differed in emphasis according to the priorities identified by each school. The total number of strategies targeting resilience and protective factors over the three year intervention period ranged from 27 to 39 per school (School A: 6-14 per year; School B: 4-12 per year; School C: 2-17 per year). Of the strategies implemented across the three schools, $26-53 \%$ addressed the curriculum, teaching and learning domain; 31-56\% ethos and environment; and 16-21\% partnerships and services.

\section{Resilience and protective factor scores}

The combined median resilience factor score for the three schools at follow up (18.17) was significantly greater compared to that at baseline $(18.00)(p<0.01)$. Similarly, the median protective factor score for the three schools combined at follow up (17.67) was significantly greater than that at baseline $(17.25)(p<0.01))$ (Table 3). On an individual school basis, at follow up a significantly greater median resilience factor score was evident for School A only $(p<0.01)$, with a trend toward a greater resilience factor score at follow up for School B. Significantly greater median protective factor scores were evident for Schools A $(p<0.01)$ and B $(p<$ $0.05)$ at follow up.

\section{Tobacco, alcohol and marijuana use prevalence}

At follow up, the proportion of all students that reported substance use for each of the 6 outcome measures was significantly lower than that at baseline (Table 4). For smoking outcomes, the proportion of students in all three schools combined who reported: ever smoking was $23.8 \%$ less $(p<0.01)$; smoking in the last three months was $12.9 \%$ less $(p<0.01)$; and being a current smoker was $12.0 \%$ less $(p<0.01)$. The proportion of

Table 3 Overall median resilience and protective factor scores

\begin{tabular}{lccc}
\hline Overall factor scores & $\mathbf{2 0 0 2}^{\mathbf{a}}$ & $\mathbf{2 0 0 6}^{\mathbf{a}}$ & $\boldsymbol{p}$ value \\
\hline Resilience & & & \\
All schools & 18.00 & 18.17 & $<0.01$ \\
School: A & 17.83 & 18.50 & $<0.01$ \\
B & 18.00 & 18.17 & 0.07 \\
C & 17.83 & 17.83 & 0.41 \\
Protective & & & \\
All schools & 17.25 & 17.67 & $<0.01$ \\
School: A & 17.17 & 17.83 & 0.01 \\
B & 17.33 & 17.75 & $<0.05$ \\
C & 17.17 & 17.17 & 0.56 \\
\hline
\end{tabular}


Table 4 Prevalence of student tobacco, alcohol and marijuana use ${ }^{\mathrm{a} *}$

\begin{tabular}{|c|c|c|c|c|c|c|c|c|c|c|c|c|}
\hline & \multicolumn{6}{|c|}{ TOBACCO } & \multicolumn{4}{|c|}{ ALCOHOL } & \multirow{2}{*}{\multicolumn{2}{|c|}{$\begin{array}{c}\text { MARIJUANA } \\
\text { Last } 3 \text { months }\end{array}$}} \\
\hline & \multicolumn{2}{|c|}{ Ever smoked ${ }^{\mathrm{b}}$} & \multicolumn{2}{|c|}{ Last 3 months $^{c}$} & \multicolumn{2}{|c|}{ Current smoker $^{d}$} & \multicolumn{2}{|c|}{ Last 3 months ${ }^{\mathrm{e}}$} & \multicolumn{2}{|c|}{ Binge drinking $^{f}$} & & \\
\hline & $\begin{array}{c}2002 \mathrm{n} \\
(\%)\end{array}$ & $\begin{array}{c}2006 \mathrm{n} \\
(\%)\end{array}$ & $\begin{array}{c}2002 \text { n } \\
(\%)\end{array}$ & $\begin{array}{c}2006 \text { n } \\
(\%)\end{array}$ & $\begin{array}{c}2002 \text { n } \\
(\%)\end{array}$ & $\begin{array}{c}2006 \mathrm{n} \\
(\%)\end{array}$ & $\begin{array}{c}2002 \text { n } \\
(\%)\end{array}$ & $\begin{array}{c}2006 \mathrm{n} \\
(\%)\end{array}$ & $\begin{array}{c}2002 \text { n } \\
(\%)\end{array}$ & $\begin{array}{c}2006 \text { n } \\
(\%)\end{array}$ & $\begin{array}{c}2002 \text { n } \\
(\%)\end{array}$ & $\begin{array}{c}2006 \mathrm{n} \\
(\%)\end{array}$ \\
\hline \multicolumn{13}{|l|}{$\begin{array}{r}\text { All } \\
\text { students }\end{array}$} \\
\hline & $714(50.6)$ & 309 (26.8) & $352(24.9)$ & $137(12.0)$ & $334(23.2)$ & $135(11.2)$ & $687(48.7)$ & $334(29.5)$ & $483(33.8)$ & $204(17.4)$ & $231(16.3)$ & $77(6.8)$ \\
\hline \multicolumn{13}{|c|}{ School } \\
\hline A & $212(51.0)$ & $103(31.5)$ & $102(24.9)$ & $48(14.7)$ & $100(24.6)$ & $42(13.0)$ & $194(48.1)$ & $94(28.8)$ & $143(33.8)$ & $61(18.8)$ & $68(16.6)$ & $23(7.1)$ \\
\hline B & $289(50.9)$ & $120(24.6)$ & $143(25.2)$ & $52(10.5)$ & $129(22.9)$ & $54(11.0)$ & $283(49.8)$ & 151 (30.8) & $198(34.6)$ & $85(17.0)$ & $85(15.0)$ & $25(5.0)$ \\
\hline C & $213(49.9)$ & $86(25.2)$ & $107(24.4)$ & 37 (11.6) & $105(24.7)$ & $39(11.5)$ & $210(47.8)$ & $89(28.2)$ & $142(32.8)$ & $58(16.6)$ & $78(17.7)$ & $29(9.1)$ \\
\hline \multicolumn{13}{|c|}{ Grade } \\
\hline 7 & $110(29.2)$ & $31(10.6)$ & $33(8.8)$ & $9(3.1)$ & $43(11.3)$ & $7(2.2)$ & $83(22.1)$ & $31(10.8)$ & 53 (13.9) & $12(3.9)$ & $18(4.8)$ & $2(0.7)$ \\
\hline 8 & $173(50.1)$ & $63(20.5)$ & $96(27.3)$ & $25(8.1)$ & $91(25.4)$ & $30(9.5)$ & $158(45.1)$ & $62(20.3)$ & $103(29.3)$ & $33(10.7)$ & $52(14.8)$ & $17(5.6)$ \\
\hline 9 & $193(59.4)$ & $104(36.2)$ & $97(30.0)$ & 49 (17.3) & $90(27.0)$ & $50(16.8)$ & $192(58.9)$ & 105 (37.6) & $134(40.5)$ & $74(25.3)$ & $70(21.4)$ & $28(10.0)$ \\
\hline 10 & $235(65.3)$ & $111(41.4)$ & $124(34.5)$ & $54(20.5)$ & $109(29.9)$ & $48(17.7)$ & $251(70.7)$ & $136(51.9)$ & $189(52.5)$ & $85(31.6)$ & $88(24.5)$ & $30(11.4)$ \\
\hline \multicolumn{13}{|c|}{ Gender } \\
\hline Male & $339(47.4)$ & $148(27.1)$ & $159(22.1)$ & $66(12.4)$ & $160(21.8)$ & $73(12.6)$ & $361(50.3)$ & $173(32.8)$ & $266(36.7)$ & $113(20.1)$ & $125(17.3)$ & $42(7.9)$ \\
\hline Female & $375(53.9)$ & $161(26.4)$ & $188(27.4)$ & $71(11.7)$ & $174(24.6)$ & $62(9.9)$ & $318(46.6)$ & $159(26.4)$ & $217(30.8)$ & $91(14.8)$ & $102(14.8)$ & $34(5.6)$ \\
\hline \multicolumn{13}{|c|}{ * All outcomes significantly lower in 2006 compared to $2002\left(p \leq 0.01\right.$ used due to multiple testing $\left.{ }^{45}\right)$} \\
\hline \multicolumn{13}{|c|}{ a $43-100$ students answers missing per question } \\
\hline \multicolumn{13}{|c|}{ bever smoked at least a few puffs of a cigarette } \\
\hline \multicolumn{13}{|c|}{${ }^{c}$ smoked at least one cigarette on at least one day in the last three months } \\
\hline \multicolumn{13}{|c|}{${ }^{d}$ currently smokes at least part of a cigarette in a week } \\
\hline \multicolumn{13}{|c|}{ edrank at least one alcoholic drink on at least one day in the last three months } \\
\hline \multicolumn{13}{|c|}{ fdrank at least five alcoholic drinks on at least one day in the last four weeks } \\
\hline${ }^{9}$ used marijua & (1) & 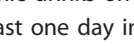 & & - & & & & & & & & \\
\hline
\end{tabular}

students who reported consumption of one or more alcoholic drinks in the last 3 months was $19.2 \%$ less ( $p$ $<0.01$ ), and consumption of five or more drinks on one or more days was $16.4 \%$ less $(p<0.01)$. Student report of marijuana use in the last 3 months was $9.5 \%$ less $(p<$ 0.01 ).

Similarly, the proportions of students in each individual school, the proportions of males and females, and the proportions of students in each grade that reported substance use for each of the six outcome measures was significantly lower at follow up than at baseline (Table 4).

\section{Discussion}

This pilot study sought to describe the potential effectiveness and feasibility of a novel comprehensive resilience and protective factor-based intervention on adolescent resilience and substance use. The results suggest that the intervention approach has the potential to decrease the extent of tobacco, alcohol and marijuana use across all students. In addition, the results confirm the feasibility of implementing such an intervention inclusive of a range of explicit adoption strategies within existing school practice. Given the importance of such behaviours to adolescent health, as well as the implications for educational practice in schools, a more rigorous controlled evaluation of the intervention is warranted to confirm the potential suggested by these findings.

Resilience theory was first developed to explain why some disadvantaged children were able to succeed in a context of high personal and environmental risk, whereas other children did not $[23,24]$. Previous studies have suggested an ability to strengthen the resilience and protective factor characteristics of a number of population groups other than adolescents $[64,65]$. For example, a controlled trial with college students has reported $5 \%-10 \%$ increases in resilience following a four week intervention [65]. Similarly, in a non-controlled study implemented in primary schools, significant increases in self-esteem, and school and family connection of $23-38 \%$ were reported following a five month resilience-based intervention [64]. The findings also extend those of a non-controlled evaluation of the program that formed the basis of the intervention implemented in this study [41]. In that analysis, significant increases in school connection, autonomy experience and help-seeking among adolescents were reported, but not for self-esteem [41]. Although such studies have suggested an ability to increase student resilience and protective factor scores, the clinical significance of such increases is unknown. 
Although statistically significant, only modest improvements were found in resilience and protective factors in this study (1-2 point increase). However such a level of improvement at a group or population level may be important from a public health perspective [66]. Further research is recommended of the effect of a resilience intervention such as that described in this study. Similarly, research focused on the standardisation of the resilience measure in an Australian high school population is also recommended.

Given the limited evidence regarding the efficacy of school-based interventions in reducing tobacco, alcohol and marijuana use, the observed differences in prevalence for all six substance use measures in this study are promising. Although the ability to compare study findings is limited due to methodological differences between studies, the observed differences in this study appear larger than the positive effect sizes in previous studies [34,38-42]. For example, in a controlled trial of a protective factor intervention designed to reduce substance use in a cohort of Grade 6 students in the USA, $2 \%$ absolute reductions in tobacco (intervention $28 \%$ verses control 30\%) and marijuana use (intervention $8 \%$ verses control 10\%) were observed at 3 year follow up [42]. Similarly, in a five and a half year follow up of a randomised controlled trial comparing the effects of two family and school interventions on tobacco, alcohol and marijuana use, relative reductions of $12-21 \%$ were reported in the prevalence of smoking initiation and $23 \%$ for marijuana initiation [38]. The $47-51 \%$ and $58 \%$ relative differences found in this study compare favourably to such previous study outcomes.

Similarly, despite the normal developmental trajectories of substance use where prevalence of use increases with age $[9,11-13]$, and the variable intervention exposure across grades, positive substance use results were achieved in this study across all grades, schools and both genders for all outcome measures. These results contrast the inconsistent group effects found in previous resilience focused studies [34,38-42]. For example, as discussed previously, a controlled protective factor intervention in 26 Australian high schools was able to demonstrate decreases in either smoking or marijuana use at follow up, but not for others $[39,40]$. Similarly, a non-controlled resilience and protective factor intervention in 15 Australian high schools was able to demonstrate decreases in smoking, alcohol or marijuana use in only a limited number of grade and gender groups examined [41].

Whilst consistent decreases in health risk behaviours were observed across all schools, the same was not evident in resilience and protective scores with one school's median score remaining unchanged (school c) despite implementing a similar number of intervention strategies. Future studies, inclusive of measures of implementation fidelity, are required to better determine the association between resilience and substance use, including the changes in both and developmental influences.

The extent to which the various elements of the intervention (for example, the explicit inclusion in this study of strategies that addressed both resilience and protective factors, the use of a health promoting schools approach [22] and the inclusion of strategies to enhance intervention adoption) or the variable intervention dose across schools contributed to the observed outcomes that other studies have not been able to demonstrate is unknown. Further research to determine the differential contribution of such factors on 'school culture' [22], resilience and protective factors, substance use and the association between such outcomes would be of benefit.

Interpretation of the study results should be viewed in light of a number of its characteristics. First, the noncontrolled study design and the use of cross sectional data preclude the drawing of causal links between the intervention and the observed outcomes. Although the design does not allow for such attribution, comparison with data from regularly conducted state-wide secondary school surveys suggest that the differences in substance use observed in this study exceed a general declining trend in use across New South Wales [11]. Based on such survey data, the absolute proportion of all 12 to 16 year old students in the state, and all such students, who reported 'ever smoking' decreased by 7\% (39\% to $32 \%$ for both populations) between 2002 and 2005 [11], compared to the $24 \%$ absolute difference between 2002 and 2006 observed in this study. The finding that the observed differences in substance use exceeded temporal trends at the state level strengthens the possibility that they may be attributable to the intervention.

Similarly, due to the study design it is unknown whether characteristics of the participating schools or students had an impact on the observed results. It is possible that the greater effect found in this study is due to the particularly low level of disadvantage in the community in which the schools were located. Alternatively, it has been argued that modifying health risks among disadvantaged populations is more difficult, as evidenced by their greater prevalence of health risk behaviours [10]. However the extent to which the level of disadvantage contributed to the effect sizes found is unknown.

Similarly, whilst data suggests that a proportion of students change schools each year across the state [67], the extent to which the rates of such movement occurred in the study schools is not known. During the study period the number of students increased in two of the three schools. Whilst students leaving the school during the study period would not be expected to have an impact 
on the study outcomes, the entry of new students to the schools during the study period has the potential to have had an impact due to reduced exposure to the intervention. As the effect of this would be to diminish the effect size of the intervention, the reported results could be considered to be a conservative estimate of effect.

Second, whilst the consent rates achieved in this study are typical for school-based research using active consent [68], the risk of non-response bias has been suggested to increase substantially once participation rates fall below 80\% [69]. Previous studies have reported nonresponding children to have a higher prevalence of health risk behaviours [70], whilst others report inconsistent or no differences in health risk behaviour prevalence [71]. If such an effect occurred, the potential exists that the lower the response rate at follow up may have contributed to the reduction in substance use however the extent to which this may have influenced the findings is unclear.

Third, the small number of participating schools limits the generalizabilty of the results to the broader population of schools. Additionally, the three participating schools are located within one community and the extent to which these results could be generalised to other disadvantaged schools or the broader population of schools is unknown. Future research is required that assesses the efficacy of the intervention in both the general population and high risk populations. Similarly, future studies should include the collection of data regarding the ethnicity of students in order to examine any differential intervention effects for students of different cultural backgrounds.

Finally, as the study relied on adolescent self report of health risk behaviours, the validity of the outcome measures is unknown [72]. Whilst a number of studies have reported that adolescent self report of tobacco use corresponds well with biochemical markers of tobacco smoking [73], options to increase the accuracy of self report exist. The bogus pipeline approach [74] and other methods of data collection, such as web based surveys, have been suggested to have higher participation rates and to increase the reporting of substance use $[75,76]$.

\section{Conclusions}

Despite these limitations, the results of this study confirm the feasibility, and suggest the potential, of a resilience based intervention approach with the inclusion of explicit adoption strategies, in reducing the unacceptably high tobacco, alcohol and marijuana use among adolescents. To further investigate the potential of this approach, future research employing a more rigorous controlled research design across a larger range of schools is required. In the event that such rigorous research confirms this potential, subsequent studies seeking to establish the relative effectiveness and cost effectiveness of the intervention elements is warranted.

\section{Acknowledgements}

This project was undertaken with the support of Hunter New England Population Health, the Hunter Institute of Mental Health, and infrastructure support from the Hunter Medical Research Institute, with funding from the NSW Drug Summit. We also acknowledge the student and staff of participating schools

\section{Author details}

${ }^{1}$ Hunter New England Population Health, Hunter New England Area Health Service, New South Wales, Australia. ${ }^{2}$ The University of Newcastle, New South Wales, Australia. ${ }^{3}$ Hunter Medical Research Institute, New South Wales, Australia. ${ }^{4}$ Newcastle Institute of Public Health, New South Wales, Australia. ${ }^{5}$ Hunter Institute of Mental Health, Hunter New England Area Health Service, New South Wales, Australia.

\section{Authors' contributions}

RKH: Performed the data analysis and drafted the manuscript. JD: Participated in the design and coordination of the study, and the critical revision of the manuscript. MF: Participated in the implementation of the intervention, helped in the drafting and participated in the critical revision of the manuscript. JB: Participated in the interpretation of the data and the critical revision of the manuscript. TH: Participated in the acquisition, analysis and interpretation of data and the critical revision of the manuscript. JW: Conceived of the study, participated in its design and coordination, helped draft the manuscript and participated in the critical revision. All authors read and approved the final manuscript.

\section{Competing interests}

The authors declare that they have no competing interests.

Received: 24 November 2010 Accepted: 24 September 2011

Published: 24 September 2011

\section{References}

1. Lopez AD: Global burden of disease and risk factors Washington D.C.: Oxford University Press; 2006.

2. Begg S, Vos T, Barker B, Stevenson C, Stanley L, Lopez AD: The burden of disease and injury in Australia 2003. PHE 82 Canberra: AlHW; 2007.

3. Mowery PD, Brick PD, Farrelly MC: Legacy First Look Report 3: Pathways to established smoking: Results from the 1999 National Youth Tobacco Survey Washington, DC: American Legacy Foundation; 2000.

4. US Department of Health and Human Services: Preventing tobacco use among young people: A report of the Surgeon General Atlanta, Georgia: US Department of Health and Human Services, Public Health Service, Centers for Disease Control and Prevention, National Center for Chronic Disease Prevention and Health Promotion, Office on Smoking and Health; 1994.

5. DiFranza JR, Savageau JA, Fletcher K, O'Loughlin J, Pbert L, Ockene JK, McNeill AD, Hazelton J, Friedman K, Dussault G, Wood C, Wellman RJ: Symptoms of tobacco dependence after brief intermittent use: the Development and Assessment of Nicotine Dependence in Youth-2 study. Arc Pediat Adol Med 2007, 161:704-10.

6. Centre for Epidemiology and Research: The health behaviours of secondary students in New South Wales 2002 Sydney: NSW Department of Health; 2004

7. Grant BF, Dawson DA: Age at onset of alcohol use and its association with DSM-IV alcohol abuse and dependence: results from the National Longitudinal Alcohol Epidemiologic Survey. J Subst Abuse 1997, 9:103-10.

8. Australian Institute of Health and Welfare: Australia's young people: their health and wellbeing 2003 Canberra: Australian Institute of Health and Welfare; 2003.

9. Adolescent Health Research Group: Youth'07: the health and wellbeing of secondary school students in New Zealand. Technical Report Auckland: The University of Auckland; 2008. 
10. Australian Institute of Health and Welfare: 2007 National Drug Strategy Household Survey: first results Canberra: AlHW; 2008.

11. Centre for Epidemiology and Research: New South Wales School Students Health Behaviours Survey: 2005 Report Sydney: NSW Department of Health; 2007.

12. Currie C: Inequalities in young people's health: health behaviour in schoolaged children (HBSC) international report from the 2005/2006 survey Scotland: WHO Regional Office for Europe; 2008.

13. Johnston LD, O'Malley PM, Bachman JG, Schulenberg JE: Monitoring the future. National results on adolescent drug use: overview of key findings, 2007 (NIH Publication No. 08-6418) Bethesda, MD: National Institute on Drug Abuse; 2008

14. Patton GC, Glover S, Bond L, Butler H, Godfrey C, Di PG, Bowes G: The Gatehouse Project: a systematic approach to mental health promotion in secondary schools. Aust NZ Psychiat 2000, 34:386-593.

15. Rutter M, Maughan B, Mortimore P, Outson J, Smith A: Fifteen thousand hours: Secondary schools and their effects on children London: Open Books; 1979 .

16. Foxcroft DR, Ireland D, Lister-Sharp DJ, Lowe G, Breen R: Primary prevention for alcohol misuse in young people. Cochrane DB Syst Rev 2002, CD003024

17. Faggiano F, Vigna-Taglianti FD, Versino E, Zambon A, Borraccino A, Lemma P: School-based prevention for illicit drugs' use. Cochrane DB Syst Rev 2005, CD003020

18. Stewart-Brown S: What is the evidence on school health promotion in improving health or preventing disease and, specifically, what is the effectiveness of the health promoting schools approach? Copenhagen: WHO Regional Office for Europe (Health Evidence Network report); 2006.

19. Thomas R, Perera R: School-based programmes for preventing smoking. Cochrane DB Syst Rev 2006, 3:CD001293.

20. Crone MR, Reijneveld SA, Willemsen MC, van Leerdam FJ, Spruijt RD, Sing RA: Prevention of smoking in adolescents with lower education: a school based intervention study. J Epidemiol Commun H 2003, 57:675-80.

21. Bisset S, Markham WA, Aveyard P: School culture as an influencing facto on youth substance use. J Epidemiol Commun H 2007, 61:485-90.

22. West $P$, Sweeting $H$, Leyland A: School effects on pupils' health behaviours: evidence in support of the health promoting school. Res Papers Educ 2004, 19:261-91.

23. Fergus S, Zimmerman MA: Adolescent resilience: a framework for understanding healthy development in the face of risk. Annu Rev Public Health 2005, 26:399-419.

24. Harvey J, Delfabbro PH: Psychological resilience in disadvantaged youth A critical overview. Aust Psych 2004, 39:3-13.

25. Catalano RF, Berglund ML, Ryan JAM, Lonczak HS, Hawkins JD: Positive Youth Development in the United States: Research Findings on Evaluations of Positive Youth Development Programs. Ann Am Acad Pol Soc Sci 2004, 591:124.

26. Greenberg MT: Promoting resilience in children and youth: preventive interventions and their interface with neuroscience. Ann N Y Acad SCi 2006, 1094:139-50.

27. Masten AS: Ordinary magic. Resilience processes in development. Am Psychol 2001, 56:227-38.

28. Luthar SS, Cicchetti D, Becker B: The construct of resilience: a critical evaluation and guidelines for future work. Child Dev 2000, 71:543-62.

29. Greenberg MT, Weissberg RP, O'Brien MU, Zins JE, Fredericks $L$, Resnik $H$, Elias MJ: Enhancing school-based prevention and youth development through coordinated social, emotional, and academic learning. Am Psychol 2003, 58:466-474

30. Benard B: Protective factors in the family, school, and community Portland, OR: Western Center for Drug-Free Schools and Communities; 1991.

31. Benard B: Fostering Resiliency in Urban Schools Virginia: Association for Supervision and Curriculum Development; 1996.

32. Bernat DH, Resnick MD: Healthy youth development: science and strategies. J Public Health Man 2006, Suppl:S10-S16.

33. Toumbourou JW: Drug Prevention Strategies: A Developmental Settings Approach Prevention Research Evaluation Report Number 2 Melbourne: Australian Drug Foundation; 2002

34. MindMatters Evaluation Consortium: Report of the MindMatters (National Mental Health in Schools Project) Evaluation Project, vols. 1-4 Newcastle: Hunter Institute of Mental Health; 2000.
35. Resnick MD, Bearman PS, Blum RW, Bauman KE, Harris KM, Jones J, Tabor J, Beuhring $T$, Sieving RE, Shew M, Ireland M, Bearinger LH, Udry JR: Protecting adolescents from harm. Findings from the National Longitudinal Study on Adolescent Health. JAMA 1997, 278:823-32.

36. Wiefferink CH, Peters L, Hoekstra F, Dam GT, Buijs GJ, Paulussen TG: Clustering of health-related behaviors and their determinants: possible consequences for school health interventions. Prev Sci 2006, 7:127-49.

37. Bond L, Butler H, Thomas L, Carlin J, Glover S, Bowes G, Patton G: Social and school connectedness in early secondary school as predictors of late teenage substance use, mental health, and academic outcomes. $J$ Adolesc Health 2007, 40:357, e9-357.e18.

38. Spoth RL, Randall GK, Trudeau L, Shin C, Redmond C: Substance use outcomes $51 / 2$ years past baseline for partnership-based, family-school preventive interventions. Drug Alcohol Depen 2008, 96:57-68.

39. Bond L, Thomas L, Coffey C, Glover S, Butler H, Carlin JB, Patton G: Longterm impact of the Gatehouse Project on cannabis use of 16-year-olds in Australia. J Sch Health 2004, 74:23-9.

40. Bond L, Patton G, Glover S, Carlin JB, Butler H, Thomas L, Bowes G: The Gatehouse Project: can a multilevel school intervention affect emotional wellbeing and health risk behaviours? J Epidemiol Commun H 2004, 58:997-1003.

41. Hazell T: MindMatters: evaluation of the professional development program and school-level implementation Newcastle: Hunter Institute of Mental Health; 2006.

42. Piper DL, Moberg DP, King MJ: The Healthy for Life project: Behavioral outcomes. J Prim Prev 2000, 21:47-73.

43. Cowen EL, Durlak JA: Social policy and prevention in mental health. Dev Psychopathol 2000, 12:815-34

44. Lister-Sharp D, Chapman S, Stewart-Brown S, Sowden A: Health promoting schools and health promotion in schools: two systematic reviews. Health Technol Assess (Winchester, England) 1999, 3:1-207.

45. Gottfredson DC, Gottfredson GD: Quality of school-based prevention programs: results from a national survey. J Res Crime Deling 2002, 39:3-36.

46. Wagner EF, Tubman JG, Gil AG: Implementing school-based substance abuse interventions: methodological dilemmas and recommended solutions. Addiction 2004, 99:Suppl-19.

47. Australian Institute of Health and Welfare: Rural, regional and remote health Canberra: AlHW; 2004

48. Centre for Epidemiology and Research: Australian Bureau of Statistics Population Estimates (HOIST) Sydney: New South Wales Department of Health; 2010.

49. Trewin D: Information Paper Census of Population and Housing SocioEconomic Indexes for Areas: Australia 2001 Canberra: Australian Bureau of Statistics: Commonwealth of Australia; 2003.

50. MindMatters Evaluation Consortium: MindMatters: A Mental Health Promotion Resource for Secondary Schools Commonwealth of Australia; 2000.

51. The University of Newcastle: Rock and Water Program 2007.

52. Shochet IM, Dadds MR, Holland D, Whitefield K, Harnett PH, Osgarby SM: The efficacy of a universal school-based program to prevent adolescent depression. J Clin Child Psychol 2001, 30:303-15.

53. Wilson KD, Kurz RS: Bridging implementation and institutionalization within organizations: proposed employment of continuous quality improvement to further dissemination. J Public Health Manag Pract 2008, 14:109-16

54. Lezotte LW, Skaife RD, Holstead MD: Effective schools: only you can make a difference All Star Publishing: 2002.

55. Bond L, Glover S, Godfrey C, Butler H, Patton GC: Building capacity for system-level change in schools: lessons from the Gatehouse Project. Health Educ Behav 2001, 28:368-83.

56. International Union for Health Promotion and Education: Achieving Health Promoting Schools: Guidelines for promoting health in schools 2009.

57. Sheehan M, Cahill H, Rowling L, Marshall B, Wynn J, Holdsworth R: Establishing a role for schools in mental health promotion: the MindMatters Project Sydney: McGraw-Hill; 2002

58. Sun J, Stewart D: Development of population-based resilience measures in the primary school setting. Health Educ 2007, 107:575-99.

59. Pagano M, Gauvreau K: Multiple Comparisons Procedures California, US: Duxbury; 2000

60. SAS Institute Inc: SAS Software Version 8.2 for Windows New York: Carry, NC; 2001 
61. Kutash K, Banks S, Duchnowski A, Lynn N: Implications of nested designs in school-based mental health services research. Eval Program Plann 2007, 30:161-71.

62. Siddiqui $\mathrm{O}$, Hedeker D, Flay BR, Hu FB: Intraclass correlation estimates in a school-based smoking prevention study. Outcome and mediating variables, by sex and ethnicity. Am J Epidemiol 1996, 144:425-33.

63. New South Wales Department of Education and Training: Statistical Compendium 20062006.

64. King KA, Vidourek RA, Davis B, McClellan W: Increasing self-esteem and school connectedness through a multidimensional mentoring program. J Sch Health 2002, 72:294-9.

65. Steinhardt $\mathrm{M}$, Dolbier $\mathrm{C}$ : Evaluation of a resilience intervention to enhance coping strategies and protective factors and decrease symptomatology. J Am Coll Health 2008, 56:445-53.

66. Crosby RD, Kolotkin RL, Williams GR: Defining clinically meaningful change in health-related quality of life. J Clin Epidemiol 2003, 56:395-407.

67. Australian Bureau of Statistics: 3412.0 Migration, Australia, 2007-08 2009.

68. Tigges BB: Parental consent and adolescent risk behavior research. J Nurs Scholarship 2003, 35:283-9.

69. Dillman DA: Mail and internet surveys: the tailored design method New York: John Wiley \& Sons; 2000

70. Henry KL, Smith EA, Hopkins AM: The effect of active parental consent on the ability to generalize the results of an alcohol, tobacco, and other drug prevention trial to rural adolescents. Eval Rev 2002, 26:645-55.

71. White VM, Hill DJ, Effendi Y: How does active parental consent influence the findings of drug-use surveys in schools? Eval Rev 2004, 28:246-60.

72. Evans RI, Hansen WB, Mittelmark MB: Increasing the validity of self-reports of smoking behavior in children. J Appl Psychol 1977, 62:521-3.

73. Post A, Gilljam H, Rosendahl I, Meurling L, Bremberg S, Galanti MR: Validity of self reports in a cohort of Swedish adolescent smokers and smokeless tobacco (snus) users. Tob Control 2005, 14:114-7.

74. Murray DM, Perry CL: The measurement of substance use among adolescents: when is the 'bogus pipeline' method needed? Addict Behav 1987, 12:225-33.

75. Kypri K, Gallagher SJ: Incentives to increase participation in an Internet survey of alcohol use: a controlled experiment. Alcohol Alcoholism 2003, 38:437-41.

76. Wang YC, Lee CM, Lew-Ting CY, Hsiao CK, Chen DR, Chen WJ: Survey of substance use among high school students in Taipei: web-based questionnaire versus paper-and-pencil questionnaire. J Adolesc Health 2005, 37:289-95.

\section{Pre-publication history}

The pre-publication history for this paper can be accessed here: http://www.biomedcentral.com/1471-2458/11/722/prepub

doi:10.1186/1471-2458-11-722

Cite this article as: Hodder et al:: A school-based resilience intervention to decrease tobacco, alcohol and marijuana use in high school students. BMC Public Health 2011 11:722.

\section{Submit your next manuscript to BioMed Central and take full advantage of:}

- Convenient online submission

- Thorough peer review

- No space constraints or color figure charges

- Immediate publication on acceptance

- Inclusion in PubMed, CAS, Scopus and Google Scholar

- Research which is freely available for redistribution

Submit your manuscript at www.biomedcentral.com/submit
Biomed Central 